\title{
Clinical Significance of Pathological and Anatomical Findings in Cone Beam CT Scans of the Maxillary Sinus
}

\author{
Eunice Kihara1, Mark Chindia', Tom Ocholla1, Mohamed Parker² \\ ${ }^{1}$ Department of Oral \& Maxillofacial Surgery, Oral Pathology \& Oral Medicine, University of Nairobi, Nairobi, \\ Kenya \\ ${ }^{2}$ Department of Diagnostics and Radiology, University of Western Cape, Cape Town, South Africa \\ Email: eunik20@yahoo.com
}

Received 20 April 2014; revised 23 May 2014; accepted 30 May 2014

Copyright (C) 2014 by authors and Scientific Research Publishing Inc.

This work is licensed under the Creative Commons Attribution International License (CC BY).

http://creativecommons.org/licenses/by/4.0/

(c) (i) Open Access

\section{Abstract}

Objective: To determine the range and prevalence of pathological conditions and demonstration of significant anatomical structures in the maxillary sinuses using the cone beam computerized tomographic (CBCT) scan. Methodology: Case series of 60 CBCT scans of the maxillae. Results: Forty $(67 \%)$ of the scans were of female patients while the rest $(20,33 \%)$ were of males. Remarkably, the majority of the scans were requested for those patients who sought dental implant fabrication. Overall, 35 (58\%) scans demonstrated pathological features while $8(13 \%)$ demonstrated significant anatomical structures. Pathological features included mucosal thickening in $26(43 \%)$, polypoid lesions in $9(15 \%)$, total antral opacification in $1(2 \%)$ and foreign body in $1(2 \%)$. The commonest anatomic feature was dental root protrusion into the maxillary sinuses in $8(13 \%)$. Conclusion: The CBCT imaging is an important tool for investigating the maxillary sinuses for pathology and the demonstration of the associated anatomic relations.

\section{Keywords}

Cone Beam CT, Maxillary Antrum, Oral Pathology

\section{Introduction}

The cone beam computed tomography (CBCT) is an advanced form of three-dimensional imaging which was pioneered by Mozzo et al. 1998 and Aral et al. 1999. It is custom-designed for the evaluation of hard tissues in the craniofacial area and has been in use since 1998 [1] [2]. The equipment uses a round or rectangular 
cone-shaped X-ray beam centered on a 2-dimensional (2D) detector. Image is acquired through a single 360degree rotation of the X-ray source and a detector which moves synchronously around the head of the patient. At certain degree intervals, single projection 2D images are acquired leading to the projection data. Software programmes integrating the cone-beam algorithm are applied to these projection data to generate a 3-dimensional (3D) volumetric dataset. This can give 3D, multiplanar (axial, coronal, saggital) and panoramic images, which are free of superimpositions as compared to conventional 2D radiographs [3]-[8]. Compared to the conventional CT, CBCT unit is smaller, cheaper, involves a quick scan time and provides isotropic voxel resolution. The field of view varies from (height $\times$ width) $4 \times 4 \mathrm{~cm}$ to $23 \times 17 \mathrm{~cm}$ [1] [8] [9]. Notably, the radiation dose varies depending on the equipment, field of view (FOV) and selected technique. Nevertheless, the effective radiation dose is much higher than that of conventional dental radiography [9] [10]. Cone beam CT lacks a soft tissue window hence hindering the assessment of head and neck malignancy. Therefore, it is best suited for the assessment of bone and dental hard tissues [10] [11].

Cone beam CT imaging has been applied in implantology, orthodontics, maxillofacial surgery and in the assessment of dentoalveolar pathology [12]. The scans often cover wide areas which may be outside the dental practitioners' area of interest such as the neck, intracranial structures, the paranasal sinuses and other airway spaces [13]. Previous CBCT studies have in fact demonstrated a high yield of pathological findings in the airway [14]-[17].

The maxillary sinuses may manifest diverse pathological conditions including inflammatory reactions, antral polyps, retention cysts, neoplasms, lesions arising from trauma and other displaced objects [3] [18]. The demonstration of these features is useful when designing evidence-based management. Furthermore, the appreciation of the sinus associated anatomical structures including tooth roots in three dimensions can enhance focused delineation of other pathology. We analyzed archived CBCT scans to determine the range and prevalence of pathological conditions manifesting in the maxillary sinuses in addition to demonstrating significant anatomical findings.

\section{Material and Method}

The study involved case series of 60 archived CBCT scans at a private imaging centre in Nairobi, Kenya. The examinations had been performed utilizing a Cone Beam Computed Tomographic Unit CS 9000C 3D extraoral imaging system (Kodak) with a small focused field of view (FOV). The study included all the CBCT scans that were done since the installation of the CBCT machine in October 2010 to August 2012.

The CS 3D imaging software 3.2.9 was used to analyze the images which were reconstructed to obtain axial, sagittal and coronal views which could be viewed at an interval of $0.2 \mathrm{~mm}$. Panoramic and 3D views were likewise reconstructed. Due to the small FOV, two or three images (volumes) were separately acquired and stitched together in order to cover a large part of the jaw. The scans of the maxillae partially covered the alveolar region, the maxillary sinuses and the nasal cavity. The study was approved by Kenyatta National Hospital/University of Nairobi-Ethics and Research Committee (KNH/UON-ERC); Approval number, P279/05/2012.

\section{Results}

There were 97 CBCT scans that were retrieved, majority 61 (63\%) of the scans were done on female and 36 (37\%) on male patients, the age was not indicated in some of the request forms; however 92 (95\%) scans had a permanent dentition. Most $(60,62 \%)$ of the scans were of the maxilla hence they were included in the study. Majority of the maxillary scans (40,67\%) were those of female cases while only 20 (33\%) were of males. Remarkably, the majority of the scans were requested for those patients who sought dental implant fabrication. Out of the 60 scans examined, 40 (67\%) of them demonstrated significant features among which 35 (58\%) were pathological while $8(13 \%)$ were significant anatomical structures. The range and prevalence of all the significant features is depicted in Table 1. Mucosal thickening (43\%) constituted the commonest pathological feature (Figure 1) followed by polypoid lesions (15\%) (Figure 2). In $2 \%$ of the cases, a foreign body was demonstrated in the antral floor (Figure 3). The significant anatomical structure was the protrusion of tooth roots into the sinus as shown in Figure 4.

\section{Discussion}

When planning to perform elective procedures such as the provision of dental implants in the maxillae, it is im- 
Table 1. Pathological and anatomical findings of maxillary CBCT scans.

\begin{tabular}{|c|c|c|c|c|c|c|}
\hline FINDINGS & Scans & $\%$ & female & $\%$ & Male & $\%$ \\
\hline Total maxillary scans & 60 & $100 \%$ & 40 & $67 \%$ & 20 & $33 \%$ \\
\hline NO FINDINGS & 20 & $33 \%$ & 14 & $23 \%$ & 6 & $10 \%$ \\
\hline ANATOMICAL FINDINGS & 8 & $13 \%$ & 6 & $10 \%$ & 2 & $3 \%$ \\
\hline Roots protruding into the antrum & 8 & $13 \%$ & 6 & $10 \%$ & 2 & $3 \%$ \\
\hline PATHOLOGICAL FINDINGS & 35 & $58 \%$ & 22 & $37 \%$ & 13 & $22 \%$ \\
\hline Mucosal thickening & 26 & $43 \%$ & 15 & $25 \%$ & 11 & $18 \%$ \\
\hline Polypoid lesions & 9 & $15 \%$ & 4 & $7 \%$ & 5 & $8 \%$ \\
\hline Opacifiedantrum & 1 & $2 \%$ & 1 & $2 \%$ & 0 & $0 \%$ \\
\hline Foreign body & 1 & $2 \%$ & 1 & $2 \%$ & 0 & $0 \%$ \\
\hline OTHERS & 3 & $5 \%$ & 2 & $3 \%$ & 1 & $2 \%$ \\
\hline Concha hypertrophy & 3 & $5 \%$ & 2 & $3 \%$ & 1 & $2 \%$ \\
\hline Deviated septum & 1 & $2 \%$ & 1 & $2 \%$ & 0 & $0 \%$ \\
\hline
\end{tabular}

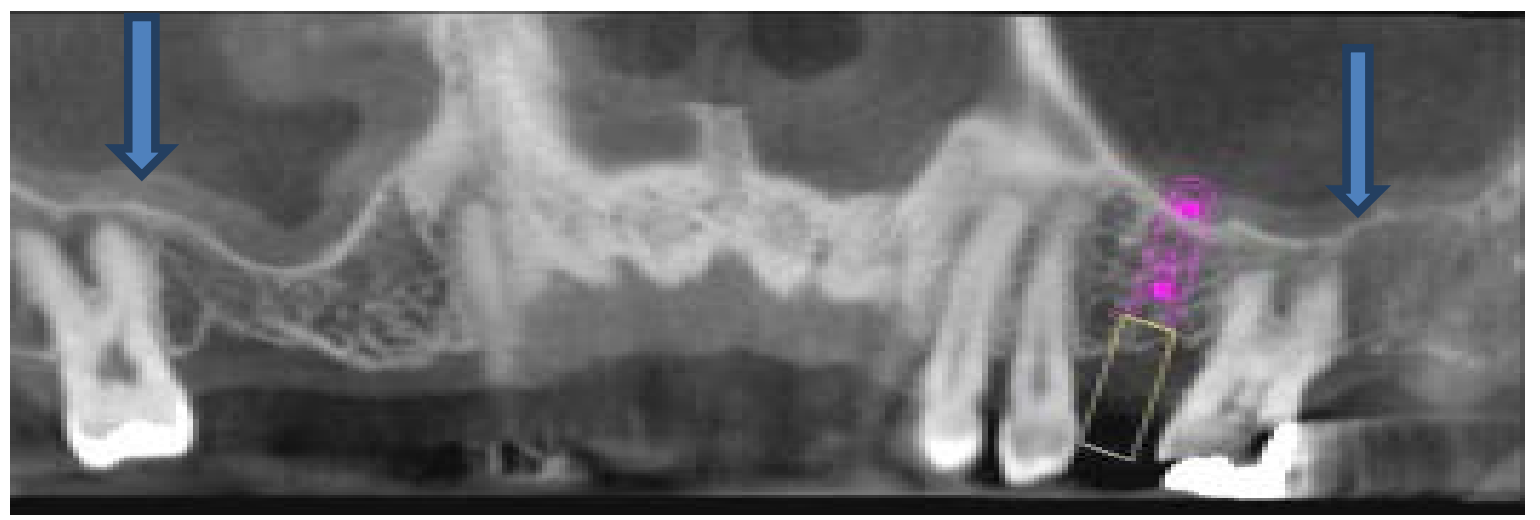

Figure 1. CBCT panoramic view of the maxilla showing bilateral mucosal thickening (arrows) in a scan indicated for implant site assessment.

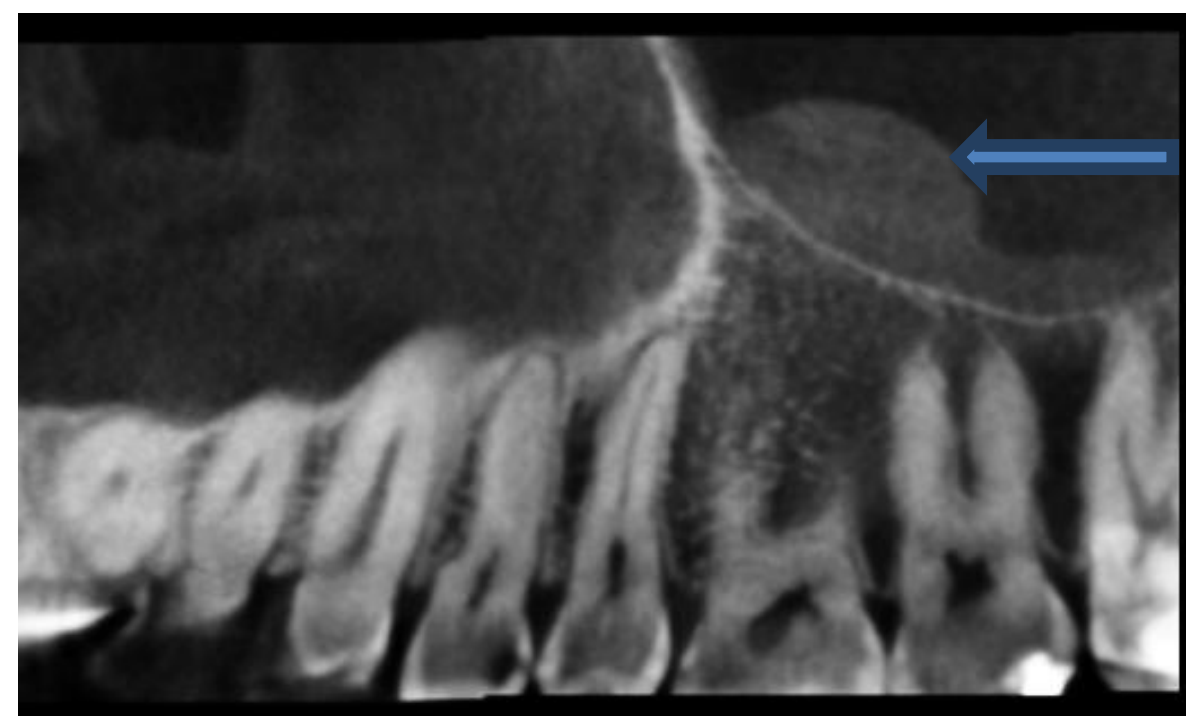

Figure 2. Polypoidantral lesion (arrow). 


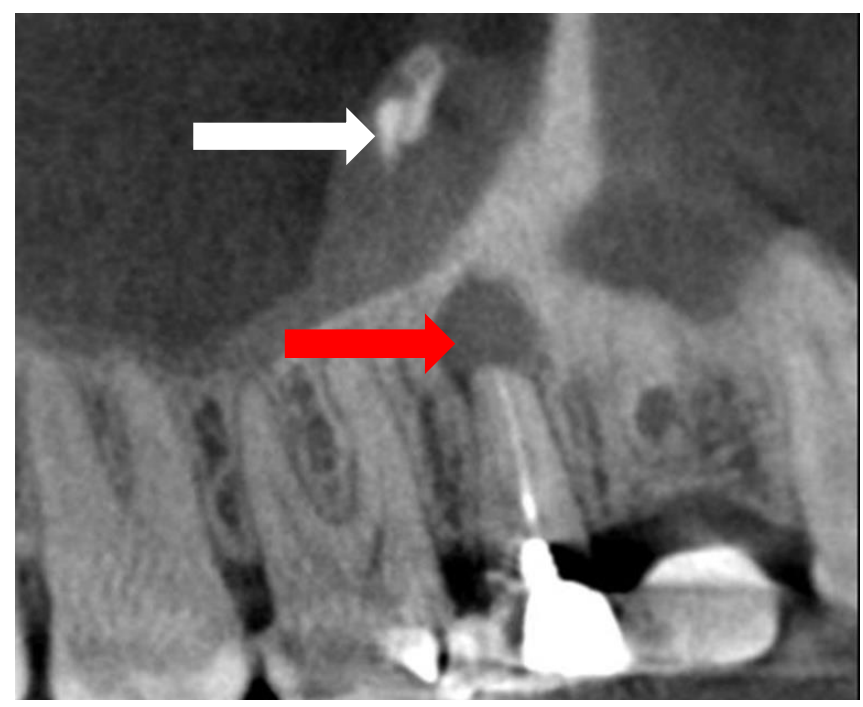

Figure 3. Foreign body (white arrow) in the sinus from a dental root filling with associated periapical pathology (red arrow) and antralmucosal inflammatory reaction.

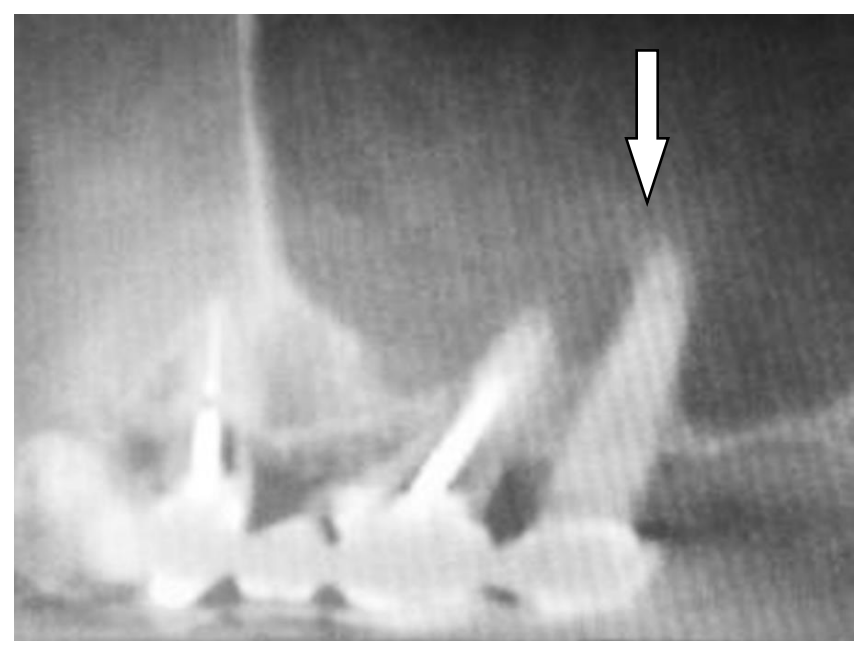

Figure 4. Dental roots protruding into the floor of the antrum.

portant to ascertain that the sinuses within them are absolutely healthy [19]. This would ensure the long-term survival of the rehabilitative structures. In the present investigation, a high yield of pathological findings has been demonstrated which is consistent with previous studies [14] [15].

Dental implant site assessment constitutes the most frequent indications for CBCT wherein the area of the nose and the maxillary sinuses can be within the imaging field [15]. It is apparent from most studies that antral mucosal thickening is the most common feature that is prominently seen on CBCT imaging. Such thickening can be a manifestation of diverse lesions due to trauma, microbial inflammation, airway conditions such as allergic rhinitis and asthma, foreign body reaction as well as early mucosal neoplastic changes [3] [17] [18]. Odontogenic infection involving periapical and periodontal tissues has also been found to play a significant role in the development of mucosal thickening and accounts for approximately $10 \%$ to $12 \%$ of cases of maxillary sinusitis [20] [21]. Based on the existing published evidence; CBCT scanning appears to demonstrate these changes much more clearly than plain radiography. In order to categorically ascertain this notion, more elaborate studies would be recommended.

The presence of polypoid lesions requires further specific investigations as this could be a manifestation of either space occupying indolent or aggressive neoplastic conditions. Further, polypoid lesions should be care- 
fully assessed and distinguished from odontogenic cysts and neoplasms which may impinge or infiltrate the antrum [3].

The 3-dimensional demonstration of the relationship of the antral floor and tooth roots is practically important since the extraction of maxillary premolars and molars has been highly associated with oroantral fistulae [22] [23]. Moreover, endodontic procedures on such teeth may lead to extrusion of dental materials into the antrum as observed in this study which may lead to further complications. Hence, immediate diagnosis and management is recommended [24]. CBCT imaging may, therefore, offer the best assessment before the execution of the procedures thereby preventing or minimizing undesirable morbidity.

In order for dental practitioners to accurately evaluate and interpret the entire CBCT data set, the American Academy of Oral and Maxillofacial Radiology Executive Committee recommends that they undergo specific training on CBCT imaging. In addition, oral and maxillofacial radiologists may assist clinicians when necessary [13].

Further, since the aetiology of maxillary sinus pathology is multifactorial, a multidisciplinary approach which may involve the dentist, oral and maxillofacial surgeon, Ear, Nose and throat (ENT) specialist, pulmonologist, allergy experts and the radiologist may be required in the diagnosis and management of significant findings. The ability to easily identify pathological changes in the antrum continues to demonstrate that CBCT could be applied in the initial evaluation of the maxillary sinus due to its low cost, less radiation and high resolution isotropic pixel. However, when CBCT imaging is not adequate, CT and MRI can be applied since CT offers a higher contrast and has a soft tissue window while MRl provides excellent visualization of the soft tissues [3].

\section{Conclusion}

The CBCT imaging is an important tool for investigating the maxillary sinuses for pathology and the demonstration of the associated anatomic relations. Dental practitioners should endeavor to accurately and promptly diagnose significant findings in the antrum as well as manage or refer patients to the appropriate clinicians.

\section{Acknowledgements}

We appreciate the Directors of DAMIC for availing the CBCT records for the study.

\section{References}

[1] Mozzo, P., Procacci, C., Tacconi, A., Martini, P.T. and Andreis, A. (1998) A New Volumetric CT Machine for Dental Imaging Based on the Cone-Beam Technique: Preliminary Results. European Radiology, 8, 1558-1564. http://dx.doi.org/10.1007/s003300050586

[2] Arai, Y., Tammisalo, E., Iwai, K., Hashimoto, K. and Shinoda, K. (1999) Development of a Compact Computed Tomographic Apparatus for Dental Use. Dentomaxillofacial Radiology, 28, 245-248. http://dx.doi.org/10.1038/sj.dmfr.4600448

[3] White, S.C. and Pharoah, M.J. (2004) Oral Radiology: Principles and Interpretation. 5th Edition, Mosby Company, St Louis, 86-594.

[4] White, S.C. (2008) Cone-Beam Imaging in Dentistry. Health Physics, 95, 628-637. http://dx.doi.org/10.1097/01.HP.0000326340.81581.1a

[5] Sikri, V.K. (2006) Fundamentals of Dental Radiology. 3rd Edition, Satishkumar Jain, CBS Publishers, New Delhi, 51-177.

[6] Kaeppler, G. (2010) Applications of Cone Beam Computed Tomography in Dental and Oral Medicine. International Journal of Computerized Dentistry, 13, 203-219.

[7] Scarfe, W.C., Farman, A.G. and Sukovic, P. (2006) Clinical Application of Conebeam Computed Tomography in Dental Practice. Journal of the Canadian Dental Association, 72, 75-80.

[8] Ludlow, J.B. and Ivanovic, M. (2008) Comparative Dosimetry of Dental CBCT Devices and 64-Slice CT for Oral and Maxillofacial Radiology. Oral Surgery, Oral Medicine, Oral Pathology, Oral Radiology, and Endodontology, 106, 106-114. http://dx.doi.org/10.1016/j.tripleo.2008.03.018

[9] Ludlow, J.B., Davies-Ludlow, L.E., Brooks, S.L. and Howerton, W.B. (2006) Dosimetry of 3 CBCT Devices for Oral and Maxillofacial Radiology: CB Mercuray, NewTom 3G and i-CAT. Dentomaxillofac Radiol, 35, 219-226. http://dx.doi.org/10.1259/dmfr/14340323

[10] Cohnen, M., kemper, J., Mobes, O., Pawelzik, J. and Modder, U. (2002) Radiation Dose in Dental Radiology. EurRa- 
diol, 12, 634-637. http://dx.doi.org/10.1007/s003300100928

[11] Macleod, L. and Heath, N. (2008) Cone-Beam Computed Tomography (CBCT) in Dental Practice. Dent Update, 35, 590-598.

[12] De Vos, W., Casselman, J. and Swennen, G.R.J. (2009) Cone-Beam Computerized Tomography (CBCT) Imaging of the Oral and Max-Illofacial Region: A Systemic Review of the Literature. International Journal of Oral and Maxillofacial Surgery, 38, 609-625. http://dx.doi.org/10.1016/j.ijom.2009.02.028

[13] Farman, A.G. (2008) American Academy of Oral and Maxillofacial Radiology Executive Opinion Statement on Performing and Interpreting Diagnostic Cone Beam Computed Tomography. Oral Surgery, Oral Medicine, Oral Pathology, Oral Radiology, and Endodontology, 106, 561-562. http://dx.doi.org/10.1016/j.tripleo.2008.07.007

[14] Ritter, L., Lutz, J., Neugebauer, J., Scheer, M., Dreiseidler, T., Zinser, M.J., et al. (2011) Prevalence of Pathologic Findings in the Maxillary Sinus in Cone-Beam Computerized Tomography. Oral Surgery, Oral Medicine, Oral Pathology, Oral Radiology, and Endodontology, 111, 634-640. http://dx.doi.org/10.1016/j.tripleo.2010.12.007

[15] Caglayan, F. and Tozoglu, U. (2012) Incidental Findings in the Maxillofacial Region Detected by Cone Beam CT. Diagnostic and Interventional Radiology, 18, 159-163

[16] Lana, J.P., Carneiro, P.M.R., Machado, V.C., de Souza, P.E.A., Manzi, F.R. and Horta, M.C.R. (2012) Anatomic Variations and Lesions of the Maxillary Sinus Detected in Cone Beam Computed Tomography for Dental Implants. Clinical Oral Implants Research, 23, 1398-1403 http://dx.doi.org/10.1111/j.1600-0501.2011.02321.x

[17] Cha, J.Y., Mah, J. and Sinclair, P. (2007) Incidental Findings in the Maxillofacial Area with 3-Dimensional ConeBeam Imaging. American Journal of Orthodontics and Dentofacial Orthopedics, 132, 7-14.

[18] Farman, A.G., Nortjé, C.J. and Wood, R.E. (Eds.) (1993) Oral and Maxillofacial Diagnostic Imaging. Mosby, St. Louis.

[19] Pignataro, L., Mantovani, M., Torretta, S., Felisati, G. and Sambataro, G. (2008) ENT Assessment in the Integrated Management of Candidate for (Maxillary) Sinus Lift. Acta Otorhinolaryngologica Italica, 28, 110-119.

[20] Vallo, J., Suominen-Taipale, L., Huumonen, S., Soikkonen, K. and Norblad, A. (2010) Prevalence of Mucosal Abnormalities of the Maxillary Sinus and Their Relationship to Dental Disease in Panoramic Radiography: Results from the Health 2000 Health Examination Survey. Oral Surgery, Oral Medicine, Oral Pathology, Oral Radiology and Endodontology, 109, e80-e87. http://dx.doi.org/10.1016/j.tripleo.2009.10.031

[21] Brook, I. (2006) Sinusitis of Odontogenic Origin. Otolaryngology, Head and Neck Surgery, 135, 349-355. http://dx.doi.org/10.1016/j.otohns.2005.10.059

[22] Yalçın, S., Öncü, B., Emes, Y., Atalay, B. and Aktaş, I. (2011) Surgical Treatment of Oroantral Fistulas: A Clinical Study of 23 Cases. Journal of Oral and Maxillofacial Surgery, 69, 333-339. http://dx.doi.org/10.1016/j.joms.2010.02.061

[23] Güven, O. (1998) A Clinical Study on Oroantral Fistulae. Journal of Cranio-Maxillofacial Surgery, 26, 267-271. http://dx.doi.org/10.1016/S1010-5182(98)80024-3

[24] Liston, P.N. and Walters, R.F. (2002) Foreign Bodies in the Maxillary Antrum: A Case Report. Australian Dental Journal, 47, 344-346. http://dx.doi.org/10.1111/j.1834-7819.2002.tb00549.x 